\title{
ZNAČILNOSTI SAMOSPEVOV KAMILA MAŠKA
}

\section{Manica špenda l (Maribor)}

Samospevi so najpomembnejše in tudi eno najobsežnejših ustvarjalnih področij Kamila Maška. ${ }^{1}$ Pisal jih je ves čas svojega skladateljskega delovanja, od leta 1845 , potem ko je komaj petnajstleten objavil v listu Illyrisches Blatt samospev v nemškem jeziku An die Sterne na tekst H. E. Coste, pa do svoje smrti leta 1859; takrat je v petem in šestem zvezku Slovenske gerlice izšel njegov Venec slovenskih pesem Doktorja Franceta Prešerna. ${ }^{2}$ $\mathrm{V}$ samospevih je dobro razvidna Maškova razvojna pot od klasicizma $\mathrm{k}$ romantiki. Samospevi Od železne ceste, V spominj Valentina Vodnika, Pod oknam ( $a$ in b), Soldaška ( $a$ in b), Prošnja, Strunam, V spominj Andreja Smoleta in Dekletam so po fakturi še izrazito klasicistični, z redkimi elementi romantike. Oblikovno so napisani kitično, $\mathrm{v}$ glavnem $\mathrm{v}$ mali enodelni, razen $\mathrm{v}$ dveh primerih, ki sta $\mathrm{v}$ dvodelni pesemski obliki. Melodična

1 Za biografske podatke glej D. Cvetko, Kaspar in Camillo Mašek, MGG, VIII, 1754, 1755 in J. Mantuani, Mašek Gašpar in Mašek Kamilo, SBL, V, 69.

${ }^{2}$ Viri o nastanku samospevov so pomanjkljivi. O času, ko so samospevi nastajali, lahko le približno sklepamo iz redkih oznak opusov, iz letnic izdaj skladb, ki so izšle v tisku oziroma iz podatkov o izdajah in posameznih izvedbah njegovih del. Prvi objavljeni Maškov samospev An die Sterne na nemški tekst H. E. Coste, ki je izšel 26. julija $1848 \mathrm{v}$ listu Illyrisches Blatt ter bil izveden na proslavi v počastitev spomina V. Vodnika 15. februarja $1849 \mathrm{v}$ Stanovskem gledališču v Ljubljani, ni ohranjen. Na isti prireditvi je bil med glasbenimi točkami na sporedu tudi samospev Ukazi. 15. februarja 1850. je v sporedu koncerta Filharmonične družbe naveden samospev za tenor in klavir L'Oeferl (Gedicht vom Klesheim, für Tenor von Camillo Maschek). 19. junija 1850. so med slovenskima igrama Kljukec je od smerti vstal in Vdova in vdovec, ki sta ju uprizorili igralci Slovenskega društva v "Ljubljanskem gledišu», izvedli tudi dvospev Ločitva. Skladba Strunam, ki je izšla $v$ petem zvezku Slovenske gerlice leta 1859 kot samospev, je izšla kot četverospev $\mathbf{s}$ klavirsko spremljavo že $\mathrm{v}$ tretjem zvezku iste revije 1852. Izvedli so jo povsej verjetnosti že prej na besedi Slovenskega društva v ljubljanskem Stanovskem gledališču 10. septembra 1848 in pozneje na Rožniku pri Ljubljani 18. julija 1849, torej štiri oziroma tri leta prej kot je bila objavljena $v$ tretjem zvezku Slovenske gerlice. Samospev An ihrem Namensfeste je Mašek napisal verjetno že pred letom 1854, ker je v rokopisu označen kot 14tes Werk, pri samospevih Winter in Toscanische Barcarole, ki sta izšla leta 1854 pri Glögglu na Dunaju, pa oznaka 30tes Werk. Novembra 1854 je bila na koncertnem sporedu Filharmonične družbe skladba Des Ritters treuer Tod - Gedicht von Theodor Körner für eine Tenorstimme, Componiert von Camillo Maschek. 7. aprila 1856 so izvedli samospev Vög'lein, mein Bote - Lied für eine Tenorstimme von Camillo Maschek. Isti samospev so 
kot tudi harmonska struktura je zelo enostavna (kvintakordi glavnih stopenj in dominantni septakord): $\mathrm{v}$ glavnem se giblje $\mathrm{v}$ okviru diatonike $\mathrm{z}$ redkimi kromatičnimi postopi in modulacijami. Dinamične in agogične označbe so redke. Tudi vloga klavirja je skromna, večinoma je omejena na spremljavo pevskega glasu, ki je še vključen v klavirski stavek.

Drugi samospevi iz omenjenega Venca (K slovesu, Mornar, Nezakonska mati, Sila spominja, Ukazi, Zapušena in Zgubljena vera z izjemo skladbe Kam in samospeva na nemški tekst An ihrem Namensfeste) so v osnovi sicer še klasicistični, v izrazu pa že romantično občuteni. Iz njih je razvidna težnja skladatelja, da se čimbolj poglobi v vsebinski pomen teksta. Kažejo že bogatejšo melodično invencijo, pa tudi pestrejšo harmonsko strukturo (alterirani akordi, zmanjšani kvintakordi in septakordi). Oblikovno prevladuje trodelnost $\mathrm{a} b \mathrm{~b}$ z izjemo Mornarja in Zapušene, pri katerih se kaže približevanje $\mathrm{k}$ prekomponiranemu tipu samospeva. ${ }^{3}$

Pevski glas je razen dveh izjem sicer še vedno vključen v klavirski stavek, vendar pa je pri omenjeni skupini samospevov klavirju dan večji pomen $\mathrm{v}$ obliki prediger, mediger in poiger. $\mathrm{V}$ predigrah nastopa navadno že tematika pevskega dela. Večji poudarek izrazu daje tudi bogatejši razpon dinamičnih in agogičnih označb.

Najzanimivejši so štirje samospevi: Kam, Je to iskreno, Toskanska barkarola in Winter, pri katerih je Mašek že prišel k prekomponirani obliki.

Samospev Kam je bil objavljen v petem zvezku Slovenske gerlice $v$ letu 1859. Je prvi prekomponirani samospev na slovenski tekst, in to na Prešernovo pesnitev Kam?:4 je za visoki glas in klavir. Oblika je trodelna A

izvajali še 27. februarja 1857; na programu je kot avtor teksta naveden E. Seidl. $\mathrm{Na}$ tem koncertu so peli tudi samospev O schneller mein Ross, Gedicht von Geibel. Leta 1859 so izšli v petem zvezku Slovenske gerlice samospevi: Strunam, Dekletam, Pod oknam a), Pod oknom b), Prošnja, Kam, Ukazi, K slovesu, Sila spominja. V šestem zvezku Slovenske gerlice pa so istega leta objavljeni samospevi: Zgubljena vera, Mornar, Soldaška a), Soldaška b), V spominj Valentina Vodnika, V spominj Andreja Smoleta, Od železne ceste, Zapušena in Nezakonska mati. Prim. D. Cvetko, Zgodovina glasbene umetnosti na Slovenskem, III, 37, 38, 39, 42, 44, 50; F. Rakuša, Slovensko petje v preteklih dobah, Ljubljana 1890, 97; A. Trstenjak, Slovensko gledališče, Ljubljana 1892, 39; Koncertni programi Filharmonične družbe, NUK, Ms.

${ }^{3} \mathrm{~V}$ samospevu Nezakonska mati so npr. prve tri kitice prekomponirane, četrta, peta in šesta pa so ponovitve prvih treh kitic. V Zgubljeni veri je četrta kitica napisana posebej, prva, druga, tretja in peta pa imajo isti napev. V samospevu An ihrem Namensfeste, ki ima trodelno obliko a b a, je pri zadnjem a menjana tonaliteta.

4 Prešernova pesnitev Kam? je prvič izšla v Ilirskem listu 30. aprila 1836 vzporedno z nemškim prevodom, pod katerim je bila opomba "Aus dem noch ungedruckten V. Hefte der Krainischen Biene». Pesnitev se v prvotnem zapisu ni ohranila. Prva objava se od natisa v Poezijah, ki ga je uporabil tudi Mašek, loči samo po pravopisnih malenkostih. Pri prvi objavi pesem še ni bila razdeljena $v$ kitice. Objava v Poezijah se popolnoma sklada z zapisi v R I in R II. F. Kidrič tolmači nastanek pesnitve tako: "Prešernova tipična kitica je sonet. Edina izjema je Kam? z dvostišji iz štiristopnih jambskih vrstic. V tem obupnem kriku, kakršnih svetovna zgodovina malo pozna, je zahteval pesnik tudi od oblike pomoč, ki mu jo sonet ni mogel dati: prva štiri dvostišja z zamolklimi a-ji v rimi utegnejo ponazarjati vso temno obupno perspektivo, zadnji dve $z$ e-jem v rimi moreta označevati bolestno ječanje iz zavesti, da ne sme pred edine oči, pred katere si želi. Po tej izjemni obliki pa je prišel do veljave zopet sonet, ki je ostal tako spojen s Prešer- 
B A. Najprej je osem taktov klavirskega uvoda $\mathrm{v}$ h-molu s kadenco. V 7 . taktu je očitna tiskovna napaka, namesto $G$ mora biti Fis. Po štiritaktnem A sledi tritaktni klavirski prehod $\mathrm{k} \mathrm{B}$ delu, ki ima 16 taktov. V 11. taktu uporabi skladatelj alteracijo akorda na dvojni dominanti v okviru diatonike. $\mathrm{V}$ 12. taktu je dvojna dominanta kot terckvartakord $\mathrm{z}$ znižano kvinto, ki jo lahko pojmujemo kot znižan fis. V 13. taktu je dominanta h-mola, ki je tretirana kot dominanta $\mathrm{H}$-dura ter preide $\mathrm{v}$ srednji del $\mathrm{B}$ dela $\mathrm{v} \mathrm{H}$-duru. 16. takt (začetek B dela) v H-duru je melodično razgiban, smisel teksta je poudarjen tudi $\mathrm{s}$ pestrejšo harmonsko strukturo, ki začenja $\mathrm{v}$ prvih štirih taktih na pedalnem tonu. V 2. taktu B dela uporabi skladatelj na zadnji osminki alterirano dominanto $\mathrm{k}$ E-duru, ki se ga $\mathrm{v}$ naslednjem taktu le bežno dotakne; v drugi poolvici istega takta nastopi $\mathrm{v}$ pevskem glasu his, ki tvori skupaj $\mathrm{z}$ akordom $\mathrm{v}$ klavirskem partu akord na III. st. cis-mola; ta se razveže $\mathrm{v}$ toniko cis-mola, kar ima $\mathrm{v}$ tem primeru funkcijo VI. st. $\mathrm{v}$ E-duru, $\mathrm{s}$ katero preide v subdominanto $\mathrm{H}$-dura; na zadnji osminki takta je navidezna molova subdominanta, ki ji preko dominantnega kvintsekstakorda in septakorda sledi vrnitev v H-dur. V 24. taktu uporabi Mašek dvojno dominanto B-dura $\mathrm{z}$ nono kot zadržkom, ki vodi v 25. taktu v D-dur. $\mathrm{V}$ tem taktu je očitna napaka $\mathrm{v}$ pevskem glasu: manjka namreč razveznik pred tonom ais. 26. in 27. takt skladatelj harmonsko in melodično ponovi, v 28. taktu sledi dominantni kvintsekstakord v Fis-duru in razvez v toniko Fis-dura. 30. takt je alterirana dominanta $v$ Fis-duru, in sicer kot terckvartakord, nakar $\mathrm{v}$ naslednjem akordu nekoliko svobodno nastopi ton g. V 33. taktu se B del zaključi v Fis-duru, kar pa lahko smatramo kot dominanto h-mola, ki ga uvede v 34. taktu kot sekstakord. Sledi ponovitev A dela z enakimi značilnostmi in zaključki.

Samospev Kam je dovolj enovit, formalno jasen, pa tudi harmonsko in melodično tehtno napisan. Prehajanje iz h-mola v Fis-dur in modulacije $\mathrm{v}$ srednjem delu so logične in ustrezajo enotnemu stilu kot tudi smislu teksta.

Samospev Je to iskreno je napisan za visoki glas in klavir, in sicer v izvirniku na nemški tekst O. Prechtlerja. Ohranjen je le $\mathrm{v}$ prevodu M. Klopčiča. 5 Oblikovno gre za prekomponirano obliko $\mathrm{s}$ formalno shemo $\mathrm{A}$ B A, pri čemer so posamezni deli različno dolgi (A 26, B 10, A 15 taktov). Uvod sestavljajo štirje takti $\mathrm{v}$ F-duru $\mathrm{z}$ alteriranim tonom $\mathrm{v}$ prvem taktu. $\mathrm{Z}$ njim nakaže skladatelj nadaljnji potek melodije. $\mathrm{V}$ 10. taktu se dotakne tonične paralele, d-mola na toniki; ta akord že predstavlja modulacijski akord II. st. v C-duru, ki mu sledi v 11. taktu dominanta v C-duru, v 12. taktu pa tonika C-dura. Nadaljnji takti do 19. takta so v C-durovi tonaliteti, 19. takt je v As-duru, ki je pripravljen s predhodnim akordom tj. dominantnim terckvartakordom. Kakor $\mathrm{v}$ drugih samospevih Mašek tudi tu

novo ljubeznijo do Julije, da je izgubil zanj privlačnost, ko je ta ljubezen bila premagana; slovenskega ni spesnil po 1838 nobenega več, a nemška samo še dva, izmed katerih pa ni noben ljubezenska izpoved.॥ Prim. A. Slodnjak, Poezije I, Ljubljana 1971, 277; F. Kidrič, Prešeren II, 1800-1838, Življenje pesnika in pesmi, Ljubljana 1938, 379; J. Kos, Zbrana dela slovenskih pesnikov in pisateljev; France Prešeren, Zbrano delo, prva knjiga, Poezije, Ljubljana 1965, 225, 226.

5 Prim. Zbornik slovenskih samospevov, Ljubljana 1953. 
uporablja v melodiji alterirane tone. Iz As-dura prehaja ponovno v 25. taktu $\mathrm{v}$ dominanto C-dura oziroma $\mathrm{v} 26$. taktu $\mathrm{v}$ toniko omenjene tonalitete. Zanimivo je melodično in harmonsko stopnjevanje: 23. takt as, 25. takt a. V 30. taktu nastopi zopet As-dur, nakar se v 32. in 33. taktu približa f-molu ter se nato $\mathrm{z}$ alterirano VII. st. C-dura ponovno vrne $\mathrm{v} 35$. taktu $\mathrm{v}$ C-dur. V 47. taktu preide v F-dur, v 43. taktu se dotakne tonične paralele, tj. d-mola, nakar podpre melodijo — v smislu označbe cresc. e accell. tudi harmonsko $\mathrm{z}$ alteriranimi akordi $\mathrm{v}$ padajoči liniji in $\mathrm{s}$ tem doseže učinkovit zaključek. Zadnji A del ponovi Mašek v obliki, ki spominja na izpeljavo. Samospev Je to iskreno je v vsakem pogledu izvrsten. Kaže na skladateljevo invencijo in tehnično znanje. Odlikujejo ga čiste melodične linije in muzikalna enovitost. Uporaba alteriranih akordov je logična, modulacije so učinkovite. Nosilec harmonije je dosledno in muzikalno logično izpeljana melodija, melodična linija pa narekuje harmonijo, kar je nakazano že $\mathrm{v}$ uvodu. Kvartsekstakordi so uporabljeni nedosledno, kar zasledimo tudi pri drugih Maškovih samospevih. Po izrazu je ta samospev romantičen in pomeni vrh Maškovega ustvarjanja na področju samospeva. $\mathrm{V}$ njem so prvič bogatejše rabljene tudi dinamične in agogične označbe: npr. v zadnjem A delu, v 44. taktu prvič accellerando, v 40. taktu so v pev.skem glasu prvič tudi okraski (grupetto), ki so tudi v klavirski spremljavi v 50. taktu (dvoložek).

Samospeva Winter in Toskanska barkarola op. 30, št. 1, 2 sta izšla $\mathrm{v}$ tisku v izdaji Zwei Lieder für eine Singstimme mit Begleitung des Pianoforte pri $\mathrm{F}$. Glögglu na Dunaju leta $1854 .{ }^{6} \mathrm{~S}$ harmonskega vidika je zanimivejši samospev Winter, ki je na nemški tekst Elise Bochini.7 Začetni štirje takti pri samospevu Winter so v g-molu, v 3. taktu je zvišana subdominanta; melodični korak, ki ga skladatelj pri tem uporablja, spominja na napolitanski sekstakord. Omenjeni štirje takti obenem naznačujejo začetek pevskega dela. Sledi osem taktov klavirskega uvoda, ki začne s 5. taktom na VI. st. g-mola, ki jo $\mathrm{v}$ naslednjem taktu razveže $\mathrm{v}$ dominanto g-mola. $\mathrm{V}$ 7. in 8. taktu sta kromatično znižana sestakorda $\mathrm{v}$ sekvenčnem redu: sekstakord v Des-duru in sekstakord v C-duru; v 9. taktu je spet akord $\mathrm{z}$ zvišano subdominanto $\mathrm{v}$ obliki zvečanega sekstakorda, ki pa $\mathrm{v} 10$. taktu ni razvezan dovolj prepričljivo, namreč v tonični kvartsekstakord. Med 9. in 10. taktom manjka dominanta g-mola. V 11. taktu je spet tonični kvartsekstakord, ki ga lahko razumemo kot zadržek pred dominanto g-mola v 12. taktu. Tu začne pevski glas z melodično in harmonsko strukturo, ki je bila nakazana $\mathrm{v}$ prvih štirih taktih: zvišana subdominanta $\mathrm{v}$ g-molu in $\mathbf{s}$ tem $\mathrm{v}$ zvezi melodični korak zmanjšane terce. Začetna pevska linija traja osem taktov z že označeno harmonsko strukturo. Harmonski postopek se odvija ostinantnem basu. Že $\mathrm{v}$ uvodu in z nastopno linijo pevskega glasu nakaže skladatelj oblikovno shemo, ki ji skoraj dosledno sledi: v smislu klasične

\footnotetext{
6 Toskanska barkarola op. 30, št. 2, v izvirniku Toscanische Barcarole, je napisana na nemški tekst S. Kapperja; v Zborniku samospevov (1953) je izšla v prevodu M. Klopiča. V rokopisu, ki ga hrani NUK, je v A-duru, v Zborniku pa v E-duru.

${ }_{7}$ Prim. F. Rakuša, ib., 90. Rokopis ni ohranjen, ohranjena je prva izdaja iz leta 1854 v NUK. Skladba je bila izvedena 2. januarja 1857. Prim. Koncertni programi Filharmonične družbe, NUK, Ms.
} 
gradnje $8+8$ ali $8+4$ itd. Nadaljevanje pevske linije obsega nadaljnjih osem taktov (od 21. do 28. takta), ki so napisani v glavnem v g-molu, začnejo pa z dominantno funkcijo, to je na VII. st. (a - c - es) g-mola. Od 21. do 24. takta uporablja skladatelj zadržke, katerih razvez pa je že naprej realiziran $\mathrm{v}$ basu, kar zmanjšuje njihovo učinkovitost. V 25. taktu nastopi napolitanski sekstakord (c - es - as), ki ga avtor ne razveže $\mathrm{v}$ dominanto, temveč $\mathrm{v}$ toniko, in to $\mathrm{v}$ kvartsekstakord, kar pa oboje ne prispeva učinkovitosti. V 27. taktu sledi ponovno akord $\mathrm{z}$ zvišano subdominanto, in sicer kot kvintsekstakord: ta je $\mathrm{v} 28$. taktu razvezan $\mathrm{v}$ dominanto g-mola, ki predstavlja modulacijski akord - toniko $\mathrm{v}$ D-duru. V 29. taktu začne nova osemtaktna linija v D-duru, ki začne z dominanto D-dura; v 30. taktu ji sledi tonika D-dura. $\mathrm{V}$ naslednjih dveh taktih nastopata izmenoma dominanta in tonika D-dura. Teh osem taktov tudi konča $\mathrm{v} 36$. taktu v D-duru. $\mathrm{S}$ predtaktom $\mathrm{v}$ 36. taktu začenja nadaljnjih osem taktov, in sicer $\mathrm{z}$ dominantno funkcijo g-mola, tj. s sekstakordom II. st. Vmes uporablja skladatelj menjalne, prehajalne note in zadržke, npr. v 40. taktu zadržek sekunde pred primo in kvarte pred terco. V 41. taktu uvaja zadnje štiri takte, spet $\mathbf{s}$ sekstakordom II. st. g-mola v dominantni funkciji, razveže ga ponovno v tonični kvartsekstakord, kadenco pa še enkrat utrdi $\mathrm{v} 44$. taktu. Naslednji trije takti (44.-47. takt) $\mathrm{v}$ klavirju so repriza uvoda, prav tako tudi naslednjih osem taktov, ki so melodična in harmonska repriza začetnih osem taktov pevske linije z že omenjenimi značilnostmi (zvišana subdominanta v g-molu in melodični korak zmanjšane terce po načinu napolitanskega sekstakorda). Takti, ki nato sledijo (56.-63. takt), so spet v D-duru. Prva polovica 59. takta prinese zmanjšani septakord (eis - gis - h - d) v obliki sekundakorda; ta je $\mathrm{v}$ tem primeru nekaka alterirana dominanta, ki pelje $\mathrm{v}$ drugi polovici takta $\mathrm{v}$ D-dur. Vrstijo se dominanta in tonika D-dura, obenem pa se nadaljuje fraza, tako da formalno in po besedilu teh osem taktov ne moremo izolirati od nadaljnjega poteka, ki sega do 77. takta; $\mathrm{v}$ razponu od 56. do 77. takta predstavljajo nekako celoto. Skladatelj je na tem mestu poskušal obdržati formalno shemo $8+8$, kar pa mu ni uspelo. Muzikalno bi lahko ta del razumeli kot nekakšno izpeljavo, kar dokazujejo harmonski premiki, pa tudi uvedba novih ritmov v spremljavi. Od 66. do 77. takta prevladuje D-dur, torej dominanta osnovne tonalitete. $V$ omenjenih taktih uporablja skladatelj ponekod kromatično nanizane prehajalne tone ali akorde. Sledi šest taktov klavirske medigre, ki začenja v D-duru. Prihod iz 80. v 81. takt je izrazita kadenca $\mathrm{v}$ D-duru, ki predstavlja $\mathrm{v}$ 81. taktu modulacijski akord - dominanto G-dura. V 38. taktu preide skladatelj v G-dur, torej $\mathrm{v}$ istoimensko tonaliteto. $\mathrm{V}$ naslednjih šestnajstih taktih (od 83. do 98. takta) prevladuje v glavnem G-dur z nekaterimi izmiki: npr. v taktih 93 in 94 se dotakne tonične paralele v e-molu. V 95. taktu nastopi sekstakord (c es - a) kot dominanta k G-duru, v 98. pa zvišana subdominanta v G-duru, $\mathrm{ki}$ je $\mathrm{v}$ nadaljnjem poteku pravilno razvezana $\mathrm{v}$ dominantni septakord in toniko G-dura. V 100. taktu je alteriran prehajalni akord, ki preide v subdominanto G-dura, ki ji sledi II. st. in kadenčni kvartsekstakord, in sicer $\mathrm{v}$ 103. taktu, nakar nastopi dominantni septakord in $\mathrm{v}$ 105. taktu tonika G-dura. Nadaljnjih osem taktov je sklep v istoimenskem duru. Skoraj identičen je $\mathrm{z}$ začetkom in vsebuje iste harmonske značilnosti, seveda $\mathrm{v}$ durovi 
tonaliteti: zvišano subdominanto in $\mathrm{v}$ 110. taktu zmanjšano terco tonike $\mathrm{v}$ obliki zmanjšanega kvintsekstakorda $\mathrm{s}$ tem, da prinese zadnji ais $\mathrm{v} 110$. taktu določeno napetost pred zaključkom v G-duru.

Samospev Winter je formalno in harmonsko pregledno grajen, njegov koncept je tudi $\mathrm{v}$ harmonskem oziru dovolj trden. Vprašljivi so le nekateri nedosledni razvezi in svobodnejša uporaba kvartsekstakordov. V oblikovnem pogledu se samospev približuje pravi prekomponirani shemi: trodelnost $\mathrm{v}$ smislu A B A je zabrisana, skladbo sestavlja vrsta osemtaktnih period. Vsak del začenja sicer $\mathrm{z}$ isto periodo, tej pa sledijo vedno nove. Posamezne dele povezujejo klavirske medigre.

V Kam kakor tudi v Toskanski barkaroli in samospevu Winter nastopa pedalni ton; v samospevu Je to iskreno le-tega ni. Iz vseh štirih samospevov je razvidna težnja $\mathrm{k}$ alteracijam, $\mathrm{h}$ kromatičnemu stavku, ki pa je $\mathrm{v}$ bistvu vendar diatoničen. Kot posebnost $\mathrm{v}$ samospevih Winter in Je to iskreno je omeniti tudi rabo akordov z zvišano sulbdominanto in melodični korak zmanjšane terce, ki je za omenjene akorde značilna ter spominja na napolitanski sekstakord $v$ melodiji.

S svojimi samospevi, posebno z zadnjimi štirimi, ki so $\mathrm{v}$ prekomponirani obliki, se je Kamilo Mašek usmeril v romantiko. Te njegove skladbe so po izrazu in umetniški vrednosti znatno kvalitetnejše od samospevov njegovih slovenskih sodobnikov in so vreden prispevek predromantiki, pa tudi začetku romantičnega obdobja slovenske glasbe.

\section{SUMMARY}

Lieder represent the most important creative field of Kamilo Mašek. They reflect the composer's development from classicism to romanticism. Published in the collection Wreath of Slovene Songs of Doctor Francè Prešern in vol. V and VI of "Slovenska gerlica» (The Slovene Turtle-Dove), 1859, they are as regards their texture mostly classicist with rare elements of romanticism. Being strophic, they are mostly written in a simple tripartite forme; the melodic and harmonic structure is uncomplicated and moves within diatonics; the role of the piano is modest, restricted mostly to accompanying the vocal sequence which is already incorporated in the piano part. Some lieder from this collection, though fundamentally classicist, appear to be already expressively romantic. Reflecting the composer's tendency to deepen the textual expressiveness they approach the »durch komponiert»-form. In four cases (Where, Toscanische Barcarole, Winter, and Is that Sincere), Mašek made aiready use of the latter form. It is in these lieder that the composer revealed an explicit romantic orientation. Regarding their expressiveness and artistic quality, they appear to surpass their slovene contemporaries, being thus a worthy contribution to the beginning of the romantic era in Slovene music. 